\title{
ERRATUM
}

\section{Erratum to: Distribution of vitamin D binding protein expressing neurons in the rat hypothalamus}

\author{
Gustav F. Jirikowski • Ulrike W. Kaunzner • \\ Abeer El Emmam Dief · Jack D. Caldwell
}

Published online: 28 November 2009

(C) Springer-Verlag 2009

Erratum to: Histochem Cell Biol (2009) 131:365-370

DOI 10.1007/s00418-008-0540-6

Unfortunately, one of the co-author's names was misspelled in the online published article.

The correct name is Ulrike W. Kaunzner instead of Ulrike W. Kauntzer.

The online version of the original article can be found under doi:10.1007/s00418-008-0540-6.

\section{G. F. Jirikowski}

Department of Anatomy II, Friedrich Schiller Universität Jena,

PF, Jena, Germany

U. W. Kaunzner

Laboratory of Neuroendocrinology, Rockefeller University,

New York, NY, USA

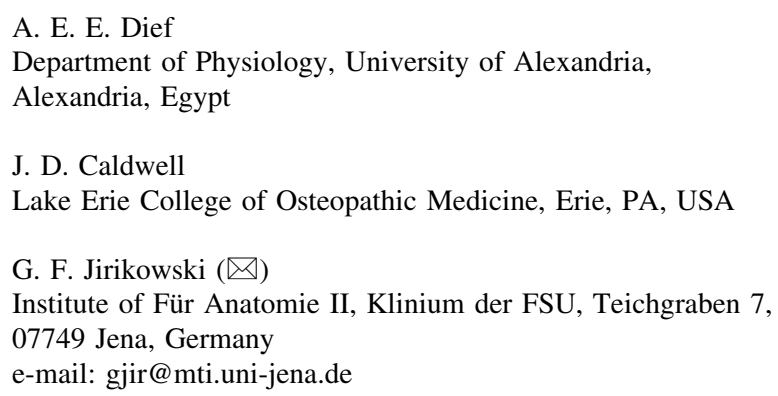

